Correction

\title{
Correction to: Some New Quaternionic Quadratics with Zeros in Terms of Second Order Quaternion Recurrences
}

Ilker Akkus* and Gonca Kizilaslan

Correction to: Adv. Appl. Clifford Algebras (2019) 29:14 https://doi.org/10.1007/s00006-018-0931-2

Unfortunately, the communicating editor was wrongly published as Dr. Cristina Elena Flaut instead of Prof. Rafał Abłamowicz.

Publisher's Note Springer Nature remains neutral with regard to jurisdictional claims in published maps and institutional affiliations.

Ilker Akkus and Gonca Kizilaslan

Department of Mathematics, Faculty of Science and Arts

Kırıkkale University

71450 Kirikkale

Turkey

e-mail: iakkus.tr@gmail.com

Gonca Kizilaslan

e-mail: goncakizilaslan@gmail.com

The original article can be found online at https://doi.org/10.1007/s00006-018-0931-2.

${ }^{*}$ Corresponding author. 